\title{
Conjugalidade negociada: elementos para compreensão do significado que casais atribuem ao dinheiro
}

\author{
Negotiated Conjugality: Elements for Understanding \\ the Meaning that Couples Attribute to Money
}

\author{
Cláudia Maria Bosetto Cenci ${ }^{1}$ \\ Jandir Jandir Pauli ${ }^{2}$ \\ Patrícia Daiane Folle ${ }^{3}$
}

Faculdade Meridional (IMED), Brasil

\begin{abstract}
Resumo. As recentes transformações socioeconômicas alteraram as relações conjugais, criando novos modelos e exigindo novas habilidades para o ajuste das relações afetivas. Assim, a gestão do dinheiro emerge como aspecto basilar para entender as relações conjugais. Objetivo deste estudo é compreender o significado que os cônjuges atribuem ao dinheiro e suas implicações na dinâmica conjugal. Para isto, foi realizada uma pesquisa exploratória de caráter qualitativo com cinco casais de classe média. As informações coletadas foram submetidas à análise de conteúdo e evidenciaram que o significado atribuído ao dinheiro pelos casais entrevistados está intrinsecamente relacionado ao modelo apreendido em suas famílias de origem, fazendo emergir conflitos e exigindo um exercício de negociação para preservação da vida conjugal.
\end{abstract}

Palavras-chave. Família de origem, conflito conjugal, finanças.

Abstract. Recent socioeconomic transformations have altered marital relationships, creating new models and requiring new skills to adjust affective relationships. Thus money management emerges as a basic aspect of understanding marital relationships. The purpose of this study is to understand the meaning that spouses attribute to money and its implications in the conjugal dynamics. For this, an exploratory qualitative study was carried out with five middle-class couples. The information collected was submitted to content analysis, and it showed that the meaning attributed to the money by the couples interviewed is intrinsically related to the model seized in their families of origin, causing conflicts to arise and requiring a negotiation exercise to preserve married life.

Keywords. Family of origin, marital conflict, finance.

\footnotetext{
${ }^{1}$ Cláudia Maria Bosetto Cenci. Programa de Pós-Graduação - IMED, Brasil. Endereço postal: Programa de Pós-Graduação em Psicologia - IMED, Rua Senador Pinheiro, 304, Passo Fundo, RS, Brasil. CEP 99070-220. E-mail: claudia.cenci@imed.edu.br

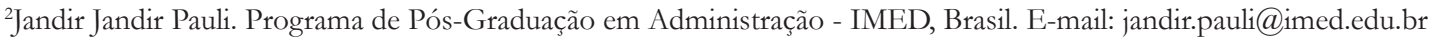

${ }^{3}$ Patrícia Daiane Folle. Escola de Psicologia - IMED, Brasil. E-mail: phatriciafolle@hotmail.com
}

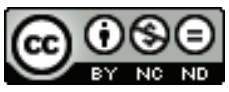

Esta obra está bajo una licencia de Creative Commons Reconocimiento-NoComercial-SinObraDerivada 4.0 Internacional. 


\section{Introdução}

O casamento é um conceito social existente em todas as culturas, cujo significado vem mudando de acordo com as ideias e interesses de cada contexto. Para se manter como instituição, o casamento precisou se adaptar conforme as constantes mudanças sociais, reinventando-se, assim, em novos formatos (Cheng, Yeoh, \& Zhang, 2015; Johnson, 2017).

Neste sentido, os casais se unem com a intenção de constituir uma vida em comum, seja pelo amor existente entre ambos e também pela continuação da própria história que vem sendo construída e planejada pelo casal (Walsh, 2016). Do ponto de vista econômico, viver (ou morar) juntos exige o desenvolvimento de um modelo econômico de gestão marcado por "conflitos cooperativos" (Singh \& Bhandari, 2012).

Neste plano, a gestão do dinheiro, em específico, emerge como aspecto central para compreensão da conjugalidade, ou seja, a forma como será manejado o dinheiro conjugal que, antes do casamento, era apenas administrado a partir das necessidades e desejos individuais (Aboim, 2006). Além disto, as transformações culturais e econômicas também influenciaram mudanças na construção da conjugalidade.

Pesquisas como Coutinho e Menandro (2010), Féres-Carneiro e Diniz Neto(2010), Guimarães (2009), Hintz (2008), Constanble (2009), Scribel, Sana e Benedetto (2007), Watzlawick, Beavin, Jackson e Cabral (2007) e Coelho e Ferreira-Valente (2016) evidenciam as mudanças contextuais e as adaptações ocorridas no relacionamento conjugal, exigindo dos cônjuges novas habilidades para ajuste entre as questões afetivas, financeiras e expectativas individuais com a relação. A conjugalidade está, portanto, imersa em relações econômicas que definem formatos e estratégias para sua manutenção. Estas estratégias exigem um trabalho constante e árduo para a manutenção da intimidade e dos elementos afetivos envolvidos na relação (Zelizer, 2005; Bandelj, Morgan, \& Sowers, 2015; Kim, 2018; Coelho, 2014).

Esta complexidade está associada à busca por um relacionamento conjugal em que coexistem motivações tradicionais atreladas ao amor romântico, sendo este um sentimento subjetivo de difícil definição e múltiplos significados, mas que no casamento se mostra vinculado à busca por uma complementaridade afetiva que proporcione segurança emocional e sensação de pertencimento (Donner \& Santos, 2016). As pesquisadoras Zordan, Falcke e Wagner (2009) sugerem que as concepções contemporâneas de casamento priorizam o desenvolvimento profissional e satisfação pessoal e, o amor romântico diminui sua força no imaginário social.

Com este plano de fundo, este estudo buscou evidências empíricas para compreensão dos significados que os cônjuges atribuem ao dinheiro. Para isto foi realizado um estudo exploratório com a realização de entrevistas semiestruturadas com cinco casais escolhidos por conveniência. $\mathrm{O}$ anterior para investigar a relação entre os aprendizados na família de origem, os conflitos implícitos que o manejo do dinheiro causa na relação conjugal e os desafios para ajustar um novo modelo de gestão que não deteriore a vida afetiva do casal.

O estudo que segue está dividido em três partes: revisão da literatura e definição das categorias de análise; apresentação do método e análise de conteúdo das informações 
coletadas e; por fim, a discussão dos resultados a partir dos eixos de análise definidos a partir da base teórica.

\section{O dinheiro e a conjugalidade}

O dinheiro permeia os laços familiares contemporâneos a ponto de ser considerado um aspecto predominante na análise desta relação. Groisman (2013b) ao relatar sobre a predominante influência do dinheiro nas famílias contemporâneas, refere que este, sendo a força maior que move o mundo, permeará os relacionamentos interpessoais e sociais, bem como as relações familiares e conjugais.

Apesar dos discursos moralistas contra as aspirações financeiras, o dinheiro se tornou sinônimo de poder, beleza, liberdade e felicidade, não sendo incomum encontrar-se discursos que aproximam o poder aquisitivo como sinônimo de felicidade (Capriles, 2005). Neste sentido, a questão do dinheiro, sempre foi tema de interesse e discussão, no entanto os estudos são sempre fundamentados sobre uma ótica moral ou religiosa ou, então, focados em como fazer para ganhar e manipular o dinheiro de forma a multiplicálo (Capriles, 2005).

Há poucos estudos sobre o significado e os efeitos deste na vida dos indivíduos. Cenci, Bona, Crestani e Habigzang (2017) referem que a interface existente entre dinheiro e conjugalidade é complexa, pois não se configura numa escolha objetiva, pois é permeada pela subjetividade individual, familiar e cultural/social. Russo (2011) pontua que o dinheiro participa da constituição da identidade dos indivíduos.

Moreira (2002) realizou um estudo sobre o significado que indivíduos atribuem ao dinheiro e concluiu que as esferas que mais se sobressaíram relacionavam-se ao poder, prazer e sofrimento. Com o intuito de obter cada vez mais dinheiro, as pessoas optam por escolhas profissionais que acreditam serem mais rentáveis economicamente, não considerando aspectos relacionados a satisfação pessoal com relação a atividade que irão desempenhar.

$\mathrm{Na}$ mesma direção, segundo Capriles (2005) é comum encontrar também profissionais já formados que abandonam sua profissão de origem em busca de um trabalho mais rentável. Esta atitude pode ocorrer em função do desejo de ter mais dinheiro ou pela angústia de não ter a quantidade de dinheiro que o indivíduo julga necessário para suas demandas pessoais e sociais.

O estudo de Coelho (2014) concluiu que a estrutura social dominante e a natureza das relações de gênero influenciam na forma como o dinheiro é manejado. Já o estudo de Jonhson (2017) concluiu que a cooperação entre os casais para o manejo do dinheiro é mais forte em casais jovens e um declínio desta cooperação ao longo do tempo, sugerindo que há uma mudança no curso de vida de uma conjugalidade associadas ao ciclo de vida dos envolvidos na relação.

Portanto, o dinheiro está tão ligado às questões da vida cotidiana que afeta os relacionamentos pessoais, familiares e conjugais. $O$ dinheiro pode ser utilizado como instrumento de manipulação entre pais e filhos, entre os cônjuges, entre irmãos e de várias outras formas (Madanes \& Madanes, 1997). 
Os problemas financeiros geralmente são apenas uma face do sintoma, ocultando conflitos mais profundos. Sendo assim, Capriles (2005) acredita ser o dinheiro o objeto representante dos anseios simbólicos da sociedade, na qual o indivíduo depara-se com inúmeras necessidades que vão muito além das imprescindíveis para a sobrevivência.

Segundo o autor, um dos maiores desafios diante deste complexo mundo do dinheiro é compreender os seus inúmeros significados, já que este é usado como um projetor de expressões que está além de meros aspectos mensuráveis. Cabe ressaltar que este aprendizado em torno das relações e do dinheiro está constantemente norteando a vida das pessoas e casamentos se desfazem muito mais em virtude das discordâncias em relação ao uso do dinheiro do que por outros motivos explicitados pelos casais no momento da separação (Madanes \& Madanes, 1997).

No relacionamento conjugal (Courduriès, 2011), os jogos de poder estão sempre presentes permeando a convivência. Os casais podem não perceber, mas estão negociando o tempo todo, mesmo quando pensam que não estão, a renda pessoal de cada cônjuge e o desequilíbrio desses jogos pode interferir na negociação intraconjugal.

Féres-Carneiro (2011) relata que os casais não percebem o dinheiro como um problema no relacionamento conjugal e os recursos financeiros são divididos de forma igualitária. Archuleta (2013) acrescenta que os casais que adotam o sistema de gestão compartilhada, em que ambos os cônjuges possuem conhecimento da renda do casal, favorece a afirmação da união conjugal, maior intimidade e afetividade.

É importante considerar, ainda, que a forma de manejo do dinheiro afeta a vida conjugal e passa a contribuir na criação uma configuração específica interferindo, inclusive, na sexualidade e na vida a dois, sendo a parte da manipulação e domínio na vivência cotidiana (Capriles, 2005). Em outros termos, os usos e manejos do dinheiro podem ser importantes mecanismos para compreender não somente os modelos existentes, mas podem ser a base para compreensão das relações de poder e de diversas manifestações de violência no espaço da vida conjugal.

\section{Método}

\section{Delineamento}

Trata-se de uma pesquisa qualitativa, transversal e descritiva. Por ser uma pesquisa com delineamento descritivo, indicará as categorias temáticas que emergiram das entrevistas, contextualizando-as por meio das verbalizações dos participantes da pesquisa (Creswell \& Clark, 2013).

\section{Instrumentos}

Utilizou-se, como instrumento para coleta de dados, uma entrevista semiestruturada, formulada a partir dos principais pressupostos teóricos encontrados na literatura revisada sobre o tema da pesquisa, dinheiro e conjugalidade. As questões norteadoras foram: 1) Como os casais viam os seus pais manuseando o dinheiro quando eram crianças? 2) Como

cada cônjuge usavam o dinheiro quando eram solteiro? 3) Como o casal utiliza o dinheiro depois de casados? 
Tabela 1

Perfil sociográfico dos participantes

\begin{tabular}{|c|c|c|c|c|c|}
\hline Casais & Idade & $\begin{array}{l}\text { Tempo } \\
\text { casados }\end{array}$ & Função/Profissão & Escolaridade & Renda \\
\hline \multirow{2}{*}{ Casal 1} & Ele 27 & \multirow{2}{*}{6 anos } & Ela: Saúde & Ela: nível técnico & Ela: $1.100,00$ \\
\hline & Ela 25 & & Ele: Eletricista & Ele: nível técnico & Ele: $2.500,00$ \\
\hline \multirow{2}{*}{ Casal 2} & Ele 23 & \multirow{2}{*}{5 anos } & Ela: Saúde & Ela: superior completo & Ela: $2.700,00$ \\
\hline & Ela 27 & & Ele: Comércio & Ele: superior incompleto & Ele: $1.900,00$ \\
\hline \multirow{2}{*}{ Casal 3} & Ele 27 & \multirow{2}{*}{7 anos } & Ela: Aux. Admin. & Ela: Ensino médio & Ela: 980,00 \\
\hline & Ela 25 & & Ele: Eletricista & Ele: nível técnico & Ele: $1.600,00$ \\
\hline \multirow{2}{*}{ Casal 4} & Ele 25 & \multirow{2}{*}{6 anos } & $\begin{array}{l}\text { Ela: Operador } \\
\text { telemarketing }\end{array}$ & Ela: Ensino médio & Ela: 890,00 \\
\hline & Ela 23 & & Ele: Administrador & Ele: superior incompleto & Ele: $2.200,00$ \\
\hline \multirow{2}{*}{ Casal 5} & Ele 32 & \multirow{2}{*}{5 anos } & Ela: Aux. Admin. & Ela: Ensino superior & Ela: $1.400,00$ \\
\hline & Ela 24 & & Ele: Autônomo & Ele: Superior incompleto & Ele: $2.000,00$ \\
\hline
\end{tabular}

Fonte: elaborado pelos autores (2018).

\section{Participantes}

Participaram do estudo cinco casais heterossexuais casados com tempo de união de pelo menos, cinco anos, independente de dogma religioso, escolaridade, cor e etnia. A tabela a seguir apresenta os participantes da pesquisa.

Procedimentos de coleta de dados

Os cinco casais participantes foram selecionados pelo critério de conveniência, sendo indicados pela rede relacional dos pesquisadores com o efeito "bola de neve" (snowball). Iniciou-se as entrevistas com um casal que aceitou participar. Após a entrevista, este casal indicou outro casal e assim por diante. Um pesquisador realizou ligações telefônicas informando aos possíveis participantes indicados sobre o objetivo da pesquisa e convidouos para participar.

Diante do aceite, as entrevistas foram agendadas, segundo a disponibilidade dos casais e, ocorreram na residência dos mesmos. A entrevista foi gravada e, posteriormente, transcrita na íntegra. Esta pesquisa fez parte de um projeto maior intitulado "Dinheiro, casais e famílias ao longo do ciclo vital familiar" a pesquisa foi aprovada pelo Comitê de Ética em Pesquisa (CEP) sob parecer CAAE 44191015.0.0000.5319. O mesmo seguiu todas as normas previstas na Resolução no 466/12.

Os casais receberam uma cópia do Termo de Consentimento Livre e Esclarecido (TCLE), que foi lido no momento da entrevista a fim de reforçar questões como sigilo, preservação 
da identidade dos participantes e garantia de que os resultados do estudo seriam usados apenas para fins de pesquisa. Informou-se, ao casal, que a entrevista seria gravada em áudio e que, após a análise das transcrições, o áudio seria apagado. Por fim, os casais foram informados que poderiam desistir de participar da pesquisa sem quaisquer prejuízos.

\section{Análise dos dados}

As entrevistas foram transcritas na integra e os dados foram analisados pelo método de análise de conteúdo (Bauer \& Gaskell 2002; Creswell \& Clark, 2013) que segue as seguintes etapas: a) Pré-análise: refere-se a leitura flutuante do material transcrito. $\mathrm{O}$ pesquisador lê e ouve várias vezes as entrevistas; b) Exploração do material: refere-se à administração sistemática das decisões tomadas com relação a leitura anterior. Trata-se de uma fase longa e cansativa, pois configura-se em operações de codificação das entrevistas. Nesta etapa, dois pesquisadores classificaram o conteúdo das entrevistas em aspectos semelhantes e deram nomes às categorias; e c) Tratamento dos resultados, inferência e interpretação: refere-se à elaboração de categorias temáticas para discussão.

\section{Resultados}

Após a análise das entrevistas emergiram três categorias para discussão. As categorias serão apresentadas e discutidas na sequência do texto. Elas foram nominadas da seguinte forma: Categoria 1: Repetição do modelo implícito e/ou explícito aprendido na família de origem; Categoria 2: Conflitos conjugais implícitos e Categoria 3: Formas de manejo do dinheiro a partir da conjugalidade.

\section{Categoria 1: Repetição do modelo implícito el ou explícito aprendido na família de origem}

A primeira categoria faz alusão ao aprendizado que os cônjuges tiveram com suas famílias de origem no que refere ao manejo do dinheiro. Trata-se da forma como estes viam os pais manuseando o dinheiro e, posteriormente reproduzindo na sua conjugalidade o modelo aprendido. Entre os casais entrevistados, alguns cônjuges referem não terem ouvido seus pais falarem sobre dinheiro ou manejarem o mesmo de forma explícita.

Porém, o que se observa nas verbalizações é a repetição de um modelo financeiro aprendido com suas famílias de origem sobre o significado do dinheiro e a forma de manejá-lo. Esta questão ficou evidenciada na fala do cônjuge masculino do Casal 1 que afirma ter observado o seu pai trabalhar e entregar o dinheiro do seu trabalho para a esposa administrar. Ela pagava as despesas da casa e administrava o restante do dinheiro ao longo do mês. Segundo ele no seu casamento atual, o manejo do dinheiro ocorre da seguinte forma "boje, lá em casa, en chego em casa e dou o dinheiro para minha esposa e ela compra o que precisa".

Fica evidente pelo relato do cônjuge masculino do Casal 1 que é na vivência familiar que ocorre o aprendizado e a internalização de um modelo de como se deve lidar com o dinheiro. Segundo Cenci, Bona, Crestani e Habigzang (2017) o aprendizado sobre o manejo do dinheiro é influenciado pelo contexto social capitalista em que os casais estão inseridos assim como as suas vivências intrafamiliares, pelas experiências de cada indivíduo vivenciadas inclusive nas suas famílias de origem e, também, pela etapa do ciclo de vida 
em que se encontra o casal. Segundo Groisman (2013b) existem valores aprendidos com a família de origem por uma via transgeracional que são nominados de lealdades invisíveis, em nome desta lealdade os cônjuges reproduzem filosofias de vida, rituais de como lidar com questões financeiras e tal lealdade pode conduzir a uma competição velada entre os casais envolvendo aspectos materiais e afetivos que podem ser medidos pelo dinheiro. Neste caso o casal tem conflitos uma vez que, desconhecendo a lealdade familiar, reproduz uma forma de manejar as finanças apreendido com as famílias de origem que prejudica a vivência harmoniosa da sua conjugalidade.

Madanes e Madanes (1997) referem que todas as famílias estabelecem regras de como seus membros devem se relacionar com as outras pessoas, porém estas regras não são faladas de forma explícita e nem discutidas. Elas são transmitidas de geração para geração e seus membros familiares repetem tais regras sem saber que estão repetindo um modelo aprendido com suas respectivas famílias de origem. Essa repetição fica clara nas entrevistas realizadas com os casais.

$\mathrm{Na}$ entrevista com o Casal 4, a esposa refere que observavam seus pais gastarem o que ganhavam com a aquisição de bens de consumo diariamente "Eu lembro que os meus pais planejavam tudo o que iam comprar. Eles priorizavam as coisas essências como alimentação, roupas, pagava as contas de água, luz e depois o que sobrava era para o lazere". Hoje, descrevendo como é feito o manejo do dinheiro na conjugalidade ela descreve: "com o nosso dinheiro, a gente paga as contas do mês, mas a gente vai guardando um dinheirinho para férias, lazer, compras".

A participante feminina do Casal 4 refere que segue o modelo aprendido em sua conjugalidade: "boje eu não gasto mais tanto com comida, minha paixão são os sapatos". Essa fala ilustra que às repetições do modelo relacionados ao manejo do dinheiro, evidenciadas reiteradamente nas verbalizações dos sujeitos da pesquisa, ocorrem de forma espontânea muitas vezes sem consciência da repetição do modelo internalizado.

Ao dar início a um relacionamento conjugal, o casal imagina estar começando uma vida a dois partindo daquele instante. O convívio entre ambos os cônjuges, pode estar começando neste momento, porém ambos viveram e tiveram experiências com suas respectivas famílias de origem que influenciaram diretamente na formação de suas identidades através das crenças, valores e comportamentos transmitidos na socialização entre seus membros que servem como referência e aprendizado de como conviver (Groisman, 2013a).

\section{Categoria 2: Conflitos conjugais implicitos}

Os cônjuges entrevistados demonstraram estratégias de como lidar com as diferentes formas de concepções que possuem sobre o dinheiro a fim de evitar conflitos mais significativos relacionados com as finanças conjugais. Ao se depararem com as diferentes formas de pensar sobre como, quando e onde gastam o dinheiro, os casais criam estratégias de gerenciamento financeiro que contemplem minimamente as necessidades de ambos. Estas estratégias são criadas com o intuito de evitar brigas conjugais recorrentes e riscos de falência do relacionamento.

Cabe ressaltar que a estratégia encontrada por cada casal é única e vale naquela união conjugal. Se estes indivíduos estivessem gerenciando suas finanças individualmente ou 
se estabelecessem outra relação conjugal, as estratégias e arranjos conjugais poderiam evidenciar diferentes configurações. Na fala dos seguintes cônjuges fica clara a estratégia encontrada por eles: "sou eu que administro tudo lá em casa, é tudo comigo" (participante masculino Casal 1); "então é o meu esposo que cuida de tudo, pois ele tem mais tempo para cuidar disso já que ele é autônomo" (Participante feminina, Casal 4)

Neste caso, ao constituir a relação a dois o casal traz para o novo cenário conjugal o aprendizado que obtiveram com suas famílias de origem, porém são duas formas diferentes de gastar o dinheiro que, ao ser partilhado no dia a dia, cada um à sua maneira pode se transformar em divergências, pois cada qual gastará o seu dinheiro de um jeito próprio e com isso terão diferentes prioridades. Para que esta união seja funcional sem haver discordâncias significativas e por consequência conflitos intransponíveis, os casais precisam criar estratégias de manejo contemplando as vivências de ambos os cônjuges e havendo uma negociação adequada ao novo núcleo conjugal.

Segundo Courduriès (2011), apesar das negociações parecerem justas do ponto de vista dos cônjuges, sob a lógica da compreensão, do amor, do companheirismo e do desinteresse, a negociação sobre as formas de utilização do dinheiro pode omitir insatisfações intraconjugais, levando a discussões que podem colocar os casamentos em risco, e por isso muitos casais preferem deixar este assunto silenciado. $\mathrm{Na}$ verbalização do Casal 3 evidencia-se um acordo mútuo, que até o momento ambos retroalimentam, com o objetivo de manutenção da união conjugal. O participante masculino do Casal 3 explicita a estratégia utilizada por ambos "não é fácil para convencer ela a segurar a mão porque se eu não tomar conta do salário dela (...) deixar ela fazer o quiser com o salário dela! Meu Deus do céu!”. Na fala da esposa: "Ah, acho que é isso... en tenho que me controlar muito porque eu gasto pra caramba é bijuteria, é um lanche, é uma roupa (...)". Nota-se nessas falas que ambos criam estratégias com o intuito de amenizar as divergências, o que não exime a possibilidade de gerar a médio e longo prazo alguma forma de conflito.

Por um lado, o cônjuge que assume o papel de gerir as demandas econômicas do casal necessitará fazê-lo repetidas vezes e, pode configurar-se numa tarefa exaustiva pelo fato de ter que controlar seu cônjuge frequentemente. Por outro lado, o cônjuge que está sendo controlado pode se sentir injustiçado por não poder gastar o próprio dinheiro, emergindo mágoas e insatisfação na relação conjugal. Outro aspecto presente nesta forma de gerenciamento das finanças é a forma assimétrica de poder estabelecida e legitimada por ambos os cônjuges, que com o passar do tempo, poderá trazer prejuízos financeiros individuais ou cônjuges dependendo do manejo do dinheiro exercido pelo cônjuge que detém o controle financeiro.

Para Meirelles e Souza (2015) o casal gerencia as finanças tendo como modelo primário aquele apreendido com suas famílias de origem assim como no contexto sócio-econômicocultural ao qual pertencem. Tal compreensão da dinâmica relacional fica evidente na fala dos cônjuges: "Ah, é tudo meio a meio, meia conta de água, meia conta de luz (...) e assim vai a gente racha tudo" (Casal 2). Este casal refere possuir o manejo do dinheiro separado e, esta forma de acordo financeiro, não possibilita o exercício do diálogo conjugal referente as finanças. Se o casal dialoga sobre seus valores e objetivos financeiros podem promover 
maior qualidade conjugal (Hart, Mosmann, \& Falcke, 2016), maior busca em conjunto de soluções para os conflitos conjugais, possibilitando maior satisfação, coesão e expressão de afeto na relação afetiva (Razera, Cenci, \& Falcke, 2015).

Existem diferentes estratégias de manejo das despesas domésticas, neste relacionamento conjugal configurou-se uma divisão de custos no qual cada cônjuge precisa necessariamente entrar com sua parte em dinheiro para o pagamento das despesas decorrentes da conjugalidade. Neste caso poderia haver divergências se um dos cônjuges, em algum momento do ciclo de vida conjugal, não conseguisse entrar com sua parte em dinheiro para pagar as despesas. Além disso, Coelho (2013), ressalta que o manejo separado do dinheiro é esperado em casais jovens e que, segundo Addo e Sassler (2010), com o aumento da intimidade conjugal o casal tende a unir as contas e, esta união financeira foi associada a maiores níveis de qualidade conjugal enquanto que, acordos individualistas estão associados à redução de sentimentos de intimidade e satisfação com a resolução de conflitos.

Segundo Courduriès (2011) com o casamento, os cônjuges passam a compartilhar e trocar opiniões construindo uma visão de mundo, com valores e objetivos em comum, e assim, de forma gradual constroem seus parâmetros financeiros. Nesta construção conjunta o casal pode deparar-se com crenças divergentes e tal divergência poderá trazer conflitos na conjugalidade. Na tentativa de resolução do conflito o casal poderá negociar superficialmente uma aparente solução.

Tal acordo (Anton, 2000) configura-se num contrato oculto num acordo nunca dito ou escrito que garante trazer harmonia para o casal. $\mathrm{Na}$ fala dos cônjuges o contrato secreto fica evidente: "O que a gente gasta, gasta junto, o que a gente compra, compra junto, nesta parte não tem diferença, eu por mim nós tínhamos até nossa conta de banco em conjunto" (participante masculino/ feminino, Casal 5).

No desenvolvimento do ciclo vital o casal evidencia diferenças no manejo do dinheiro que necessita ser esclarecida pelo casal (Meirelles \& Souza, 2015) e, com o intuito de evitar a falência conjugal, alguns cônjuges se adaptam ao gerenciamento do cônjuge. Pode-se observar na fala da participante feminina do Casal 2 a necessária adaptação de seu cônjuge ao aprendizado dela de que o dinheiro deve ser também guardado a partir do início do casamento: "Eu quando criança tinha uma poupança em meu nome feita pelos meus pais, mas a gente não mexia naquele dinheiro, ele era guardado para caso algum dia surgisse uma necessidade".

$\mathrm{Na}$ concepção de como o dinheiro deve ser usado agora na conjugalidade ela pontua a forma como o marido deve usar o dinheiro: "é, agora ele não faz só festa, ele também guarda o dinheiro pra quando surgir uma necessidade (...)". O objetivo da poupança se torna comum ao par conjugal no momento em que o homem aceita a forma de manejo do dinheiro que a esposa acredita ser o correto para o casamento. Capriles (2005) refere que ao assumir um compromisso matrimonial, na maioria das vezes, os cônjuges não estão conscientes de que precisarão negociar até mesmo a forma de gastar seu dinheiro, resultando algumas vezes em um impacto emocional.

É esperado que nos primeiros anos de casamento o casal experimente diferentes formas de gerenciamento do dinheiro e de diferentes estratégias para resolução dos conflitos 
cotidiano por ser um período de adaptação entre os cônjuges. Passada a fase inicial da relação é esperado a diminuição da expectativa e uma maior adaptação as exigências oriundas da vida conjugal e familiar, que as diferenças e os desacordos conjugais são esperados assim como as tentativas de resolução dos conflitos que caso não ocorram poderão aumentar as mágoas e culminar em distanciamento e, por vezes, em separação (Costa, Da Cenci \& Mosmann, 2016).

Os cônjuges (Madanes \& Madanes, 1997) ao longo do casamento, inevitavelmente terão que administrar às possíveis crises que surgirão em relação à competitividade, as lealdades à família de origem, as heranças e aos comportamentos aprendidos e, nem sempre conscientes, muitas vezes servem como um agravante ao conflito conjugal. Pode-se perceber na verbalização do participante masculino do Casal 3 que o conflito explicito é em função da diferença de manejo financeiro entre os cônjuges: "agora o problema é a mulher, a gente briga, briga no início do mês (...)". O motivo das brigas, segundo o participante, ocorre porque ele quer planejar os gastos enquanto ela quer gastar sem maior planejamento. $\mathrm{Na}$ fala da participante feminina pode-se observar esta afirmação:

com a mania que ele tem de ter que pagar uma conta para depois faz̧er outra, eu tô aprendendo ainda para falar a verdade porque tem muitos meses que eu quero alguma coisa e não dá pra comprar porque primeiro tem que pagar uma para depois comesar uma nova divida. Ele tem essa mania de ter tudo contado eu já não.

O conflito pode tornar-se imutável ao longo do casamento se a discussão entre os cônjuges for pautada na responsabilização do outro pelos conflitos estabelecidos e, na dinâmica relacional, mantidos por ambos. Os cônjuges, direcionam seus esforços na culpabilização do outro pela não resolução do conflito e, assim não haverá necessidade de uma reflexão sobre a sua coparticipação na construção dos mesmos.

Entretanto cabe ressaltar que os conflitos conjugais referentes ao dinheiro ocorrem com mais frequência no início da vida conjugal justamente pela necessidade de negociação dos arranjos necessários a aquela conjugalidade e, nos anos que antecedem a aposentadoria pois o casal se depara com os resultados dos arranjos realizados por eles (Cenci, Bona, Crestani, \& Habigzang, 2017).

Categoria 3: Formas de manejo do dinheiro a partir da conjugalidade

Quando criança, adolescente ou jovem o indivíduo possui uma dependência emocional e financeira dos pais que diminui gradualmente. $\mathrm{Na}$ idade adulta os indivíduos adquirem seu próprio dinheiro e com ele autonomia e liberdade para gastar. No início do casamento, uma das questões que o casal se depara está relacionada ao gerenciamento das prioridades inerentes a uma vida a dois e a liberdade diminui (Madanes \& Madanes, 1997).

Outra configuração também presente no manejo do dinheiro conjugal evidencia-se naquele indivíduo que não adquiriu uma autonomia financeira quando solteiro e delega ao outro a responsabilidade pelo gerenciamento do seu dinheiro. Tal configuração fica evidente nessas seguintes verbalizações da participante feminina:

eu, o que eu lembro da minha familia é que até uma certa idade era o meu pai quem trabalhava e sustentava a família, eu lembro que a minha mãe era totalmente dependente do meu pai. Eu, depois 
que nos casamos, eu passei todos os meus cartões para o meu esposo e, é ele quem cuida do meu dinheiro e das contas (participante feminino, Casal 3).

O modelo relacional parental com relação ao manejo do dinheiro aprendido na família de origem é repetido na conjugalidade e acordado por ambos os cônjuges como sendo uma forma de gestão do dinheiro que os dois concordam. A forma de gestão compartilhada do dinheiro indica que quanto maior é o nível de permanência na relação afetiva, maior será o diálogo sobre as finanças (Van der Lippe, Voorpostel, \& Hewitt, (2014).

Cabe ressaltar que os acordos conjugais aparentemente satisfatórios inicialmente numa relação conjugal nem sempre se configuram em um padrão equilibrado de poder de decisão entre os cônjuges e, com o passar dos anos de relação, no caso de uma separação ou de gerenciamento ilícito do cônjuge tem o poder de decisão sobre as finanças do casal, poderão com o passar dos anos resultarem em insatisfação, mágoas, ressentimentos ou danos financeiros irreparáveis.

$\mathrm{Na}$ fala a seguir também é possível visualizar outra forma de negociação entre os cônjuges:

Assim, a gente trabalha e no final do mês eu pego o meu dinheiro e pago todas as contas que eu consigo com o meu salário. Ele recebe e dá todo o salário pra mim e, eu pago todas as outras contas que faltam e o que sobra, (...) eu guardo pra passar o mês (...). Sou en que administro tudo lá em casa, é tudo comigo" (participante feminino, Casal 1).

Ao negociar as formas de investir os rendimentos do casal estes formulam estratégias com o objetivo de manter a harmonia conjugal. Tal harmonia poderá sofrer alterações quando houver crises esperadas e/ou inesperadas, como por exemplo, desemprego de um dos cônjuges, doença e mudança geográfica em função do trabalho. Em função destas crises um dos cônjuges poderá querer mudar o acordo conjugal com relação ao dinheiro e não mais exercer o papel designado a ele naquela conjugalidade.

O dinheiro está na base de toda a sociedade e da vida humana, está constantemente norteando a vida de todos os indivíduos. Para os entrevistados o dinheiro é usado para além das necessidades básicas, a maior parte dos rendimentos financeiros é direcionada ao consumo e mesmo o bem-estar está ligado ao ter dinheiro para adquirir bens de consumo. Mesmo os cônjuges que neste momento estão focados em sua formação profissional, este investimento é para no futuro retornar em forma de um salário maior tendo mais dinheiro para comprar mais. O consumo envolve ações como o ato ou finalidade de comprar bens, produtos e serviços (Nery, Meneses, \& Torres, 2012).

A sociedade está a todo instante criando novos desejos e armadilhas, ou seja, para cada necessidade satisfeita surgem outras de igual ou maior intensidade e os anseios desta são representados pelo desejo de ter um carro importado ao invés de ter um veículo como meio de transporte ou então querer uma casa na praia ou no bosque e não simplesmente ter uma um lar para morar (Madanes \& Madanes, 1997). Tal necessidade criada pode ser percebida na verbalização que segue: "Ela comprou um sapato de trežentos reais! Acho que ela usou umas quatro vezes" (participante masculino, Casal 3). O desejo de consumo está cada vez mais crescente na vida cotidiana, tendo a mídia como meio de incentivo se especializando e estudando os aspectos emocionais dos indivíduos traçando estratégias para vender produtos camuflados na promessa de felicidade. Para isso cria um mundo 
distante da realidade e atrai um número cada vez maior de consumidores que, fragilizados pelas angústias do cotidiano fogem da realidade angustiante entrando nesse universo consumista e aparentemente acalentador.

O impulso aquisitivo, segundo Capriles (2005), sempre foi um fator importante na motivação da conduta dos indivíduos sendo relevante estudar o lugar que ocupa o anseio por bens de consumo no universo das motivações humanas para compreender e extensão e a generalização do impacto econômico na vida dos sujeitos em todos os níveis da vida social. Trata-se, então, de entender de que forma os indivíduos internalizam a questão do dinheiro e do consumo em seu próprio pensamento.

Netto (2012) salienta as estratégias criadas pela sociedade moderna para atrair consumidores simulando um mundo feliz vendendo juntamente com seu produto um estilo de vida quase inatingível para a maioria dos indivíduos que, segundo Capriles (2005) passam uma vida toda atormentados em fazer dinheiro e mais, focando seus esforços a fim de adquirir bens e serviços que lhes traga a felicidade inventada pela sociedade. Tais aspirações por consumir produtos supervalorizados são também aprendidos com as famílias de origem e serão facilmente repetidos no manejo do dinheiro na conjugalidade, como expresso na verbalização: "eu lembro que os meus pais procuravam me dar sempre o melhor, melhor roupa, melhor tênis, melhor colégio" (participante masculino, Casal 5).

Minuchin, Lee e Simon (2008) escreveram sobre a influência do consumo nas famílias resultando em uma sobrecarga do trabalho, pois os pais associam a ideia de serem bons pais à medida que conseguirem proporcionar aos seus filhos bens e serviço que a sociedade materialista proporciona e com isso não tem tempo para ficarem próximos dos filhos e proporcionarem o que o autor diz ser a "cola" da vida familiar que é o sentimento de relação próxima e segura.

Capriles (2005) refere que o dinheiro possui um universo de significados subjetivos e também uma solução para pobreza sendo um recurso importante para adquirir bens valorizados pela sociedade justificando seu lugar na hierarquia nas motivações humanas. $\mathrm{O}$ autor refere ainda que o ofício de ganhar dinheiro possui vantagem sobre as demais atividades pelo fato da necessidade que os indivíduos sentem de adquirir algo que simbolize e satisfaça suas necessidades de consumo que vem desde a infância e que por outro lado nunca serão totalmente satisfeitas, pois com a era do capitalismo haverá sempre uma necessidade criada pela sociedade. Tal necessidade aprendida fica evidente na seguinte verbalização da participante feminina do Casal 1:

Quando eu tinha doze anos eu comecei a trabalhar de babá para comeşar a adquirir dinheiro para poder comprar algumas coisinhas que eu tinha vontade, tipo, pra poder comprar um tênis da moda e comprar alguma coisa diferente, um caderno mais legal, essas coisas". "A minha prioridade (quando tive o meu dinheiro) era a roupa, porque quando eu era criança muito raramente era comprado roupa (...).

Com estes resultados, este artigo procurou demonstrar como as necessidades e desejos com relação a aquisição de bens de consumo são apreendidos e desenvolvidas desde a infância nas relações que a criança vivencia no seu cotidiano relacional nos diferentes sistema e instituições a que ela pertence. É importante ressaltar que, as prioridades de 
consumo vão se modificando ao longo do desenvolvimento do ciclo de vida conjugal e familiar e, cabe ao indivíduo uma reflexão sobre as necessidades primordiais da sua história de vida e as necessidades artificialmente construídas num contexto social de consumo.

Como evidenciado nas entrevistas, se o indivíduo ao se unir em uma conjugalidade, não flexibilizar suas necessidades individuais, o exercício da conjugalidade poderá produzir complementariedades assimétricas e fomentar conflitos relacionais de difícil resolução. Essa conclusão está em consonância com as conclusões dos escritos que fundamentaram esta pesquisa, complementando a ideia de que os modelos estão estreitamente relacionados com os aprendizados obtidos nas famílias de origem e que o modelo de gestão do dinheiro que está sendo adotado pelos cônjuges está marcado por relações de poder e comumente permeados por conflito.

\section{Considerações finais}

Esta pesquisa teve como propósito investigar o significado que os cônjuges atribuem ao dinheiro e suas implicações na dinâmica conjugal. O significado monetário presente nas concepções dos cônjuges entrevistados e a forma como estes indivíduos se interrelacionam a partir do aprendizado que tiveram com suas respectivas famílias de origem, orientam as emoções e ações conjugais na gestão do dinheiro conjugal. No exercício da conjugalidade, a repetição dos padrões transgeracionais de dois modelos distintos de aprendizado poderá ficar incompatível e o casamento pode se tornar disfuncional.

Dentre as limitações do estudo destaca-se a não consideração de como algumas mudanças sociais recentes, especialmente a inserção da mulher no mercado de trabalho, alteraram as configurações de manejo de dinheiro na conjugalidade. Embora essa não tenha sido a questão desse estudo, ela contribuiria para ponderar a contribuição da transgeracionalidade na formatação dos modelos de utilização do dinheiro pelos casais. Estudos futuros poderão lançar luz a essa questão para avaliar em que medida o contexto influencia e ressignifica as relações financeiras no espaço da conjugalidade.

Outro aspecto que limita o estudo é que a escolha de casais com pouco tempo de vida conjugal permite inferências relativas sobre as diversas formatações possíveis no curso do casamento. Se, por um lado, a definição de um critério que limita a diversidade da amostra é útil para caracterizar um determinado momento, isto é, permite a compreensão do modelo que está ainda em formatação, ajustando "heranças" das famílias de origem, por outro, ele cria uma caricatura bastante específica que pode variar se analisados outros grupos. Nesta direção, estudos futuros poderiam comparar outros grupos de casais com mais tempo de convivência, ou mesmo avaliar as mudanças e conflitos ocasionados com a chegada dos filhos.

Trabalhos futuros também poderiam pesquisar sobre o significado do dinheiro no âmbito conjugal familiar, inserindo a sua relação com os filhos a partir das dimensões da educação financeira, controle gastos e formas de consumo, buscando compreender de que forma se relacionam com a economia atual. Neste interím, poderiam considerar a maneira que esta relação influencia no comportamento juvenil, especialmente através da análise dos valores, da cultura e classe social.

Considerando os aspectos acima citados, o estudo contribui para compreensão do 
significado implícito do dinheiro, seja para adquirir bens de consumo, seja para suprir as necessidades diárias, os quais servem como uma metáfora para felicidade, bem-estar e vida confortável. Tal significado atribuído ao dinheiro é originário das relações que os casais entrevistados aprenderam nas inter-relações com suas famílias de origem, e que foi reforçado com as demais inter-relações sociais que tem uma relevância significativa no desenvolvimento do padrão de interação estabelecido pelos casais.

O que em um primeiro momento, parece ser só de cunho monetário e instrumental, com o passar do tempo passa a evidenciar o conteúdo emocional subjacente a tais escolhas monetárias. Percebeu-se que, para estes casais, o significado do dinheiro é fundamentado na ideia de que assim como o amor, o dinheiro é importante na constituição do relacionamento conjugal.

\section{Referências}

Aboim, S. (2006). Conjugalidade, afetos e formas de autonomia individual. Análise Social, 41(180), 801-825.

Addo, F. R., \& Sassler, S. (2010). Financial arrangements and relationship quality in low-income couples. Family Relations, 59(4), 408-423. doi:10.1111/j.1741-3729.2010.00612.x

Anton, I. C. (2000). A escolha do cônjuge: um entendimento sistêmico e psicodinâmico. Porto Alegre, RS: Artmed Editora.

Archuleta, K. L. (2013). Couples money, and expectations: negotiating financial management roles to increase relationship satisfaction. Marriage \& Family Review, 49(5), 391-411. doi: 10.1080/01494929.2013.766296

Bandelj, N., Morgan, P. J., \& Sowers, E. (2015). Hostile worlds or connected lives? Research on the interplay between intimacy and economy. Sociology Compass, 9(2), 115-127. doi: $10.1111 /$ soc4.12242

Bauer, M. W., \& Gaskell, G. (2002). Pesquisa qualitativa com texto, imagem e som: um manual prático. Petrópolis: Vozes.

Capriles, A. (2005). Dinheiro: sanidade ou loucura. São Paulo, SP: Axis Mundi.

Cenci, C. M. B., Bona, C. S., Crestani, P. L., \& Habigzang, L. F. (2017). Dinheiro e conjugalidade: uma revisão sistemática da literatura. Temas em Psicologia, 25(1), 385-399. doi: 10.9788/TP2017.1-20

Cheng, Y. E., Yeoh, B. S., \& Zhang, J. (2015). Still 'breadwinners' and 'providers': Singaporean husbands, money and masculinity in transnational marriages. Gender, Place \& Culture, 22(6), 867-883. doi: 10.1080/0966369X.2014.917282

Coelho, L. (2013). O meu, o teu e o nosso dinheiro: Contributos para o estudo da gestão das finanças conjugais em Portugal. Revista Crítica de Ciências Sociais, (101), 89-110.

Coelho, L. (2014). My money, your money, our money: Contributions to the study of couples' financial management in Portugal. RCCS Annual Review. A selection from the Portuguese journal Revista Crítica de Ciências Sociais, (6). doi: 10.4000/rccsar.54 
Coelho, L., \& Ferreira-Valente, A. Y. (2016). Money and Marriage: Couple's Choices and their Predictors. Revista Española de Investigaciones Sociológicas (REIS), 156(156), 21 39. doi: $10.5477 /$ cis/reis.156.21

Constable, N. (2009).The commodification of intimacy: Marriage, sex and reproductive labour. Annual Review of Anthropology 38, 49-64. doi: 10.1146/annurev. anthro.37.081407.085133

Costa, C. B. da, Cenci, C. M. B., \& Mosmann, C. P. (2016). Conflito conjugal e estratégias de resolução: uma revisão sistemática da literatura. Temas em Psicologia, 24(1), 325-338.

Courduriès, J. (2011). O dinheiro no casamento: questões de gênero. Estudos Feministas, 19(2), 623-625. doi: 10.1590/S0104-026X2011000200025

Coutinho, dos S. M. S., \& Menandro, P. R. M. (2010). Relações conjugais e familiares na perspectiva de mulheres de duas gerações: "Que seja terno enquanto dure". Psicologia clínica, 22(2), 83-106.

Creswell, J., \& Clark, V. L. P. (2013). Pesquisa de Métodos Mistos. Porto Alegre: Penso.

Donner, H., \& Santos, G. (2016). Love, marriage, and intimate citizenship in contemporary China and India: an introduction. Modern Asian Studies, 50(4), 1123-1146. doi: 10.1017/S0026749X16000032

Féres-Carneiro, T., \& Diniz-Neto, O. (2010). Construção e dissolução da conjugalidade: padrões relacionais. Paidéia (Ribeirão Preto), 20(46), 269-278. doi: 10.1590/S0103863X2010000200014

Groisman, M. (2013a). A arte de perdoar. Terapia sistêmica breve no casamento e na infidelidade. Rio de Janeiro, Brasil: Núcleo de Pesquisas.

Groisman, M. (2013b). Minha família e meu dinheiro. Rio de Janeiro, Brasil: Núcleo de Pesquisas.

Guimarães, K. A. C. (2009). A Dificuldade de Comunicação do Casal. Um Olhar Sistêmico. Monografia. (Especialização em Terapia de Casais e Famílias). Universidade Católica de Goiás. Goiânia, Goiás.

Hart, J., Mosmann, C. P., \& Falcke D. (2016). Manejo do dinheiro pelo casal e infidelidade financeira. Revista Psicologia Clínica e Psicanálise, 16(1), 260-27.

Hintz, H. C. (2008). Questões Afetivas versus Questões Financeiras na Relação Conjugal. Em R. M. S. de. Macedo, Terapia Familiar no Brasil na Última Década (pp.376-382). São Paulo: Roca.

Johnson, S. (2017). 'We Don't Have This Is Mine and This Is His': Managing Money and The Character of Conjugality in Kenya. The Journal of Development Studies, 53(5), 755-768. doi: 10.1080/00220388.2016.1205729

Kim, J. S. (2018). Payments and Intimate Ties in Transnationally Brokered Marriages. SocioEconomic Review.

Madanes, C., \& Madanes, C. (1997). O Significado Secreto do Dinheiro. Campinas, Brasil: Editorial Psy. 
Meirelles, V. M., De Souza, R. M. (2015). Uso do dinheiro na vida adulta: uma perspectiva da psicologia clínica e da psicologia do dinheiro. São Paulo, Brasil: Atlas.

Minuchin, S., Lee, W., \& Simon, G. M. (2008). Dominando a terapia familiar. Porto Alegre: Artmed.

Moreira, A. (2002). Dinheiro no Brasil: um estudo comparativo do significado do dinheiro entre as regiões geográficas brasileiras. Estudos de Psicologia (Natal), 7(2), 379-387. doi: 10.1590/S1413-294X2002000200019

Nery, M. B. M., Menêses, C. A. S., \& Torres, T. K. S. (2012). Um breve ensaio da psicologia acerca do comportamento consumista na sociedade atual. Interfaces Cientificas Humanas e Sociais, 1(1), 53-62. doi: 10.17564/2316-3801.2012v1n1p53-62

Netto, B. R. (2012). O consumidor para além do seu conceito jurídico: Contribuições da filosofia, sociologia e antropologia. Dissertação de Mestrado, Universidade Federal do Rio Grande do Sul, Porto Alegre, RS, Brasil.

Razera, J., Cenci, C. M., \& Falcke, D. (2015). Manejo de dinheiro: possíveis relações com o ajustamento e a violência em casais. Perspectivas em psicologia, 19(2), 3-17.

Russo, G. (2011). Amor e dinheiro: uma relação possível? Caderno CRH, 24(61), 121-134.

Scribel, M. C., Sana, M. R., \& Di Benedetto, A. M. (2007). Os esquemas na estruturação do vínculo conjugal. Revista Brasileira de Terapias Cognitivas, 3(3), 0-0. doi: $10.5935 / 1808-5687.20070012$

Singh, S., \& Bhandari, M. (2012). Money management and control in the Indian joint family across generations. The Sociological Review, 60(1), 46-67. doi: 10.1111/j.1467-954X.2011.02047.x

Van der Lippe, T., Voorpostel, M., \& Hewitt, B. (2014). Disagreements among cohabiting and married couples in 22 European countries. Demographic Research, 31(1), 247-274.

Walsh, F. (2016). Diversidade e complexidade nas familias do século XXI. Em: WALSH, Froma. Processos Normativos da Família: Diversidade e Complexidade, (2016). Porto Alegre: Artmed.

Watzlawick, P., Beavin, J. H., Jackson, D. D., \& Cabral, Á. (2007). Pragmática da comunicaşão bumana: um estudo dos padröes, patologias e paradoxos da interação. São Paulo, Brasil: Cultrix.

Zelizer, V. (2005). The purchase of intimacy. Princeton, N. J., United States: Princeton University Press.

Zordan, E. P., Falcke, D., \& Wagner, A. (2009). Casar ou não casar?: Motivos e expectativas com relação ao casamento. Psicologia em Revista, 15(2), 56-76.

Recebido: 16 de agosto de 2017

Aceitado: 23 de abril de 2018 